\title{
Game Model To Increase Fundamental Movement Skills in Children With Mild Intellectual Disability
}

\author{
Selvi Atesya Kesumawati ${ }^{1}$, Tandiyo Rahayu ${ }^{2}$, Hari Amirullah $\mathbf{R}^{3}$, Setya Rahayu ${ }^{4}$ \\ ${ }^{1}$ Graduate School of Sport Education, Universitas Negeri Semarang, Indonesia. \\ ${ }^{2,4}$ Faculty of Sport Science, Universitas Negeri Semarang, Indonesia. \\ ${ }^{3}$ Faculty of Sport Science, Universitas Negeri Yogyakarta, Indonesia. \\ Corresponding email: husnselv@gmail.com
}

\begin{abstract}
Children with intellectual disability (ID) have problems in sesormotorik, learning and behavior that resulted in disruption of physical development of children. Most children with ID experience obstacles in responding to stimuli given the environment to perform and imitate movement. Well-designed learning is one way of directing optimal fundamental movement skills (FMS) and gaining pleasure through movement. The FMS learning model loves our body is a variation of learning that is used to help overcome problems that arise in the field on FMS learning materials. The method used in this research is the research and development of Borg and Gall, the subject of a limited-scale trial of 10 students of Intellectual disability children primary school (SDLBC), and 3 teachers. The subjects of large-scale trials amounted to 30 students in SDLB C in the third SDLB C in the city of Palembang. The FMS game model loves our body designed by researchers is expected to improve fundamental movement skills, cognitive skill, fun and attention focus of children with ID.
\end{abstract}

Keyword: fundamental movement skills, game, intellectual disability children.

\section{Introduction}

The process of education for children is an important thing that needs to get attention from various parties. Education in schools has an important role and has covered two important aspects of social aspects and individual aspects. Education also serves to influence and create a condition that allows it can help the child's development optimally. Providing education is not only intended for normal children, but children with special needs such as tunagrahita children who have physical deficiencies are also entitled to obtain a decent education, because after all the physical and mental state of a child would still need a guidance for maturing children in the environment community.

Learning is a part of education and specific, a process in which a person's environment is deliberately managed so that he can learn or engage in specific behaviors with specific conditions or to respond to specific situations (Dwiyogo, 2010:3). Meanwhile, Dimyati \& Mudjiono (2006:159) state Learning also means improving cognitive abilities, affective and student skills. These abilities are developed together with the acquisition of learning experiences. Based on expert opinion, it can be concluded that learning is part of the educational process that aims to facilitate someone in order to improve cognitive, affective and skills in achieving educational goals. There are several goals to be achieved in learning. A teacher is required to design an effective learning for learners, including learners with special needs. The purpose of learning is to develop themselves optimally by improving and improving the quality of learning through optimal learning methods and design so as to achieve the desired results.

Movement is a basic element and the nature of human life, without human motion becomes less perfect and can cause abnormalities in the body and organs, therefore movement becomes a very important need to meet the needs and survival of a child is no exception intellectual disability children. The movement undergoes a change we can observe from human birth to adulthood, from meaningless free movement to meaningful movement and meaning, from gross movement to soft movement, from irregular movement to uniform movement, and the many types of movement necessary studied and nurtured and adapted to their own needs, developments and social norms.

Physical education is an education that uses physical activity and movement as the medium. According to BSNP (2006:648) states that: Physical education is an integral part of education as a whole, aims to develop aspects of physical fitness, motion skills, 
critical thinking skills, social skills, reasoning, emotional stability, moral action, healthy lifestyle aspects, and the introduction of a clean environment through selected physical, exercise, and health activities systematically in order to achieve national education objectives.

Physcical adaptive learning is a comprehensive service delivery system designed for children with special needs to know, discover and solve problems in the psychomotor realm, since most children with special needs have problems in the psychomotor domain as a result of limited sensory abilities and limitations in academic ability. One way that can be used to overcome some basic motion problems in ID chilldren is to provide opportunities to children by developing a basic motion game model through play activities.

Play activities as a means of enhancing the fundamental movement skills of the ID children Landreth in Kottman (2011:51) listed the following objectives in child-centered play theraphy: (1) help the child enhance his or her possitives self concept, (2) help the child move to accepting more responsibility for self, (3) help the child reach enhanced levels of self acceptance, self reliance, and self direction, (4) help the child practice self directed decision making, (5) help the child feel more in control, (6) help the child increase his or her awarness of the process of coping, (7) help the child develop an internal locus of evaluation, (8) help the child learn to trust himself or herself more.

Emerson (2005) found the lack of physical activity to be a significant behavioral risk of health among people with ID. Physical activity studies of people with ID identified significant inactivity and associated behavior risks of health in a majority of this population [Moss, 2009; Temple and Stanish 2009]. Physical exercise and various sports-related activities are necessary to promote health, fitness, and psychological development among children of school age. In general, the ability to play sports and exercise is lower for children with intellectual disabilities than in children without such disabilities [Kihara \& Hashimoto, 2000]. Children with intellectual disabilities often have psychological problems associated with carrying out exercise. Moreover, their experience of exercise is limited.
The qualitative aspect of the movement displayed by the child, remains dependent on effort, ie how one combines the sharing of elements / factors (time, load, space and flow). Therefore, the idea or theme of movement is essential, meaning that in teaching the movement in children should be tailored to the characteristics of the students. According to Mutiah (2010:91) that play should be done on the initiative of the child and on the child's own decision. Play should be done with a sense of fun, so that all play activities are fun will result in a learning process in children. Meanwhile, according to Piaget in Yuliani (2009:34) said that play is an activity that is done repeatedly and cause pleasure / satisfaction for a person.

According to Yudanto (2010:47), in learning motor skills, children need basic skills experience (locomotor motion, non locomotor and manipulative). Children should learn to perform simple moves before connecting them into more difficult movements, before mastering a motion skill, children should be given the opportunity to do the exercises. Children should have the opportunity to try, correct and try again. Children will improve their motor skills based on their previous play experience. Memory plays an important role for children in learning motor skills. The child needs to recall what he or she has done in order to correct and correct it. To learn motion skills, children must combine memory or memories with previous experiences, take advantage of opportunities to try something new, and practice what they have learned (Soetjiningsih, 2002:39).

Kenneth (2007) "Play is essential to development because it contributes to the cognitive, physical, social and emotional wellbeing of children and youth. Play also offers an ideal opportunity for parents to engage fully with their children". Play is a fun activity for children. The game itself can provide an opportunity to practice the skills of the children with intellectual disability repeatedly and can develop ideas according to his own ability, therefore learning should be able to provide opportunities to play in children with intellectual disability in the school environment.

Fundamental movement competence is linked to physical activity in both children with and without disability (Barnett, Hinkley, Okely, \& Salmon, 2013). Stodden et al. (2008) 
and Capio, Sit and Abernethy (2011) noted that locomotor and manipulative skills form the foundation for future movement and are considered essential for the development of more complicated or sport-specific motor skills. Moreover, Khodaverdi, Bahram, Khalaji and Kazemnejad (2013) presented locomotor and manipulative skills as indicators of physical skills mastery consequently enabling enjoyable participation in physical activities. Li et al. (2016) studied correlates of physical activity in children with physical disabilities and showed that physical and biological factors such as physical functioning ability and gross motor function were found to be consistently associated with physical activity, suggesting that increased physical and motor functioning is associated with higher levels of physical activity.

Play is strongly affected by the the child's context, including family and peers, socioeconomic influences, and availability of time. What is concidered play by one child may seem totally innappropriate an even distasteful to another child based on his or her prior experiences and personal preferences. Play is viewed as child-initiated activity that is not structured by an adult and does not have skill acquisition as a goal (Olson \& O'Herron in Diane \&Fazio, 2008:321).

\section{Game Model}

The game "Love Our Body" is one form of game designed purposely by researchers for children with ID in Primary School (SDLB C). It is taken from one of the themes contained in the 2013 Curriculum Master Handbook. This model consists of 3 game post. Each pos has a motion assignment and uses different media and tools. Pos 1 learner walkside on a textured catwalk (synthetic smooth grass, cendol cloth mat, and a thick mat) take limbs flaschcard in the finish line, Pos 2 Skip forward (into the circle), then catapult and catch the ball, and pos 3 underhand throw the bean bag colored to the target.

This game can be implemented at the time of learning at school and can be used as a form of therapy for children with ID at home and done repeatedly so as to improve the basic motion skills of children. The benefits in this game are to stimulate the visual and tactile in the child's with ID in performing the task of motion balance and coordination (Sullivan, et al, 2012:76-77).
The game aims to: (1) improve the fundamental movement skills of the child with intellectual disabilities, walk side, skip forward and underhand throw, (2) the child can recognize and name the limbs, (3) Increases sensory children with varied textures, and (4) know letters, numbers and differentiate colors. Equipment used in pos 1;8 evamatt pieces of $30 \times 30 \mathrm{~cm}$, each modified with a different texture (finely synthesized grass, gravel, coarse grass, cendol mat, bottle cap, dacron, grain, fondant / night), flashcard of limbs, colored tape, flag (marker), and whistles.

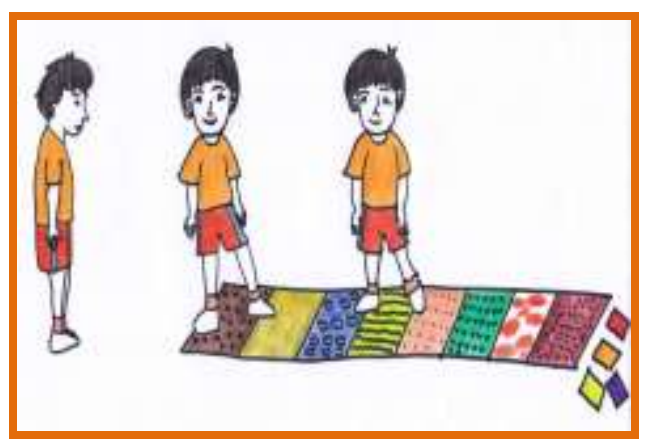

Figure 1. Game Model Pos 1

Instructions: The child stands ready behind the starting line. The child performs a left-handed movement. Then pick up one of the flashcards picturing the limbs and mention the name of the limb. After hearing the cue from the teacher (the whistle) the child immediately make a movement step foot to the right side with the left foot following it, It is endeavored to keep the child's point of view straight up to the finish line. After being in the finish line, the child takes a picture of the limb corresponding to the flashcard taken in the starting line (likening the image).

Equipment used in pos 2; 5 pieces of circle made of hose diameter $30 \mathrm{~cm}$, fabric ball diameter $30 \mathrm{~cm}$, colored tape, flag (marker), stopwatch and whistles. Instruction: The child stands ready behind the starting line. After hearing the cue from the teacher (whistle) the child immediately makes a skip forward (refusing and landing with both legs into the circle. After being in the finish line of the child make a movement of the ball to the top of the head and then catch it for 1 minute. Upon completion the child stands ready at the finish line. 


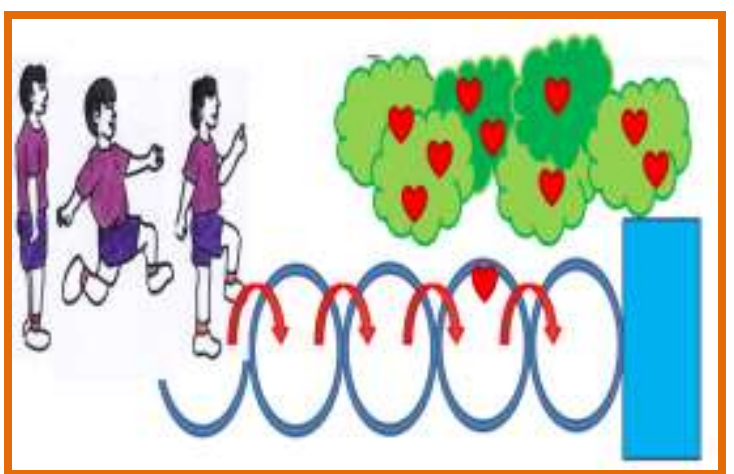

Figure 2. Game Model Pos 2

Equipment used in pos 3; Bean bag 6 pieces ( 2 red, 2 blue, 2 yellow), 3 pieces of blue, yellow, red, 60x60 $\mathrm{cm}$ evergreen as a throw target, colored tape for barring, flag (marker), and whistle. Instruction: The child stands ready behind the starting line. After the cue of the teacher, the child takes one bean bag by mentioning its color and specifies the number that matches the target color of the throw. The child performs a throwing bean bag from the bottom (underhand throw) towards the target of the throw. The child repeats the movement until the provided bean bag (6 pieces of bean bag) is on the target of the throw. After that the child stands ready at the finish line.

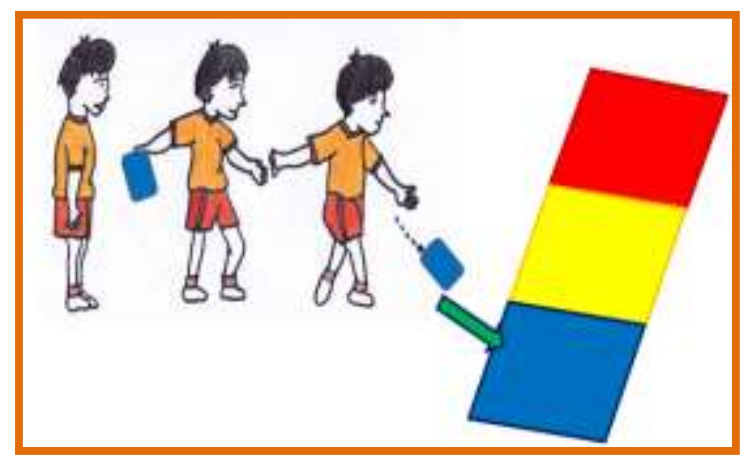

Figure 3. Game Model Pos 3

\section{Method}

This study aims to produce a product of a model fundamental movement skill game for intellectual disability children in special education using Borg and Gall's research and development process $(\mathrm{RnD})$. The subject of the limited-scale trial amounted to 10 students of grade 1 Special Education of Karya Ibu Palembang, 3 teachers (physical educator and teacher class). Extensive trials of 30 people, and 9 teachers (teacher and classroom teachers) Special Education of Palembang City (Karya Ibu, YPAC and Pembina).

\section{Results and Discussion}

The game model is piloted on 10 students and involves 3 teachers as assessors. The results of observations / assessments obtained by learners in table 1:

Table 1. The Result Pretest and Post Test Game Model On Children

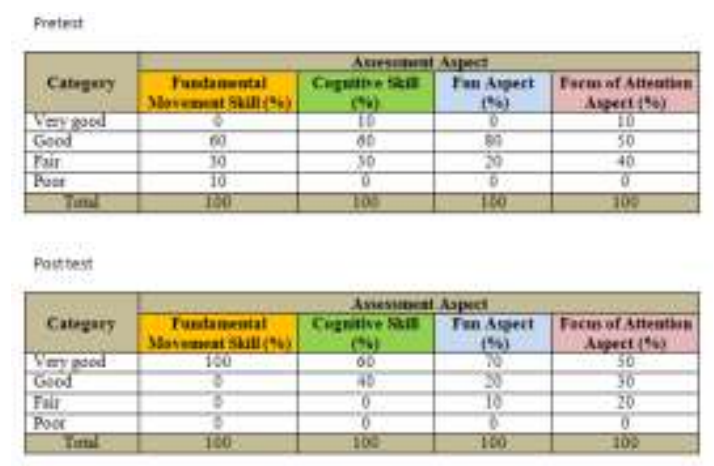

Table 2. The Result Teacher's Assessment of The Implementation Game Model

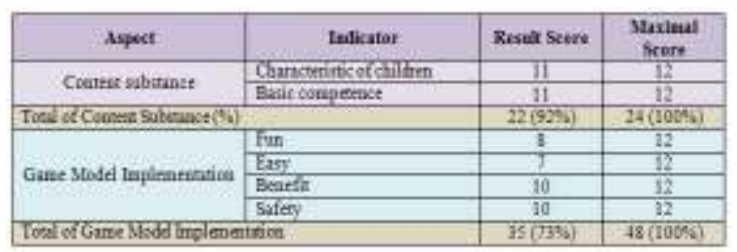

Based on the table above, the calculation of the percentage is $92 \%$ for the substance content and $73 \%$ for the implementation of the basic motion game model, so it can be concluded that the basic motion learning model through our body's love game in terms of substance content is very suitable with the characteristics of students and in accordance with basic competence, and if viewed from the aspect of implementation on a limited scale safe, easy, happy and useful. This research will continue on a wide scale.

Based on the calculation of correlation coefficients between rater, the trial data of the instrument model of FMS learning through the play of love our body on aspects of FMS, cognitive aspects, Fun aspects and focus of attention aspects are known to have a relationship between rater 1 scores and total rater scores have a positive relationship high, the relationship between rater 2 score and rater total score has a high degree of positive relationship, and also the relationship between rater 3 score and total score between rater has a high degree of positive relationship. The 
following is the validity of each aspect in table 3 below:

Table 3. The Result Validity Test Game Model

\begin{tabular}{|c|c|c|c|c|}
\hline Aped & Fater Scere & $\begin{array}{l}\text { Coefiricat } \\
\text { Cotelation }\end{array}$ & P. & Status \\
\hline \multirow{3}{*}{$\begin{array}{l}\text { Findumenal } \\
\text { Moverent Skill }\end{array}$} & Ratert-bobal falentare & 6919 & 005 & Vea \\
\hline & Fater is outal rentrscore & 0300 & 0.05 & vad \\
\hline & Rater 3- woll ranerscore & 0.880 & 0.05 & vald \\
\hline \multirow{3}{*}{ Cogritire Skill } & Rater 1-sobl mencore & 6863 & $\partial 05$ & valid \\
\hline & Rater :- seal ranericom & 8370 & 0.03 & Vasin \\
\hline & Panet i-sotil merstore & 5783 & 0.05 & vod \\
\hline \multirow{3}{*}{$\mathbf{P a}$} & Rater 1- boll ratencere & 6347 & 0.05 & vend \\
\hline & Rater 2. wotal rutericere & 2750 & 0.05 & vasd \\
\hline & Rater j- sotal talentore & 0,346 & 0.05 & VIS \\
\hline \multirow{3}{*}{$\begin{array}{l}\text { Focos of } \\
\text { Anentioa }\end{array}$} & Rater 1-sotal tistericare & 0671 & 0.05 & Vall \\
\hline & Taree 2. wotal ranerscore & 0.545 & 0.05 & vad \\
\hline & Ruter J-stal restencern & 0643 & 005 & Valid \\
\hline
\end{tabular}

Based on the results of the calculation of reliability between the rater, the experimental data of the FMS learning model instrument through the game is love our body, it is known that the four aspects of reliability value if estimated using the Alpha coefficient, by analyzing the data using Anova-General Multifacet Model, shows the coefficient and coefficient values between the rater high, as in table 4 below:

Table 4. The Result Reliability Test Game

\begin{tabular}{|c|c|c|c|}
\hline Aspect & Coefisiesil & Corficientinter riter & 5Tिए। \\
\hline Fundamental Movement Skall & 0802 & 0670 & Reliabje \\
\hline Copribve Skail & 0.823 & 0.712 & Reliable \\
\hline Fun & 0.563 & 0.759 & Reliable \\
\hline Focur of Anenticen & 0.752 & 0.603 & Reliable \\
\hline
\end{tabular}

Thus based on the reliability test statistic calculation, the instrument of FMS learning model through playing activities on love our body's on both FMS, cognitive skill, fun and focus attention on children with ID is known to have high reliability between rater, so that all instruments are stated reliable and can be used for data retrieval in empirical tests.

\section{Conclusions}

In a limited scale trial the application of the love our body game model obtained results: (1) the suitability of the substance content and the accuracy of the content included in the high category; (2) the implementation of the game model provides convenience for teachers in carrying out learning and carrying out the assessment of students, and provides security, usefulness and pleasure in learning; (3) the application of the game model can improve learning outcomes of FMS, cognitive abilities, fun and focus of attention children with ID.

\section{References}

Barnett, L., Hinkley, T., Okely, A., \& Salmon, J. 2013. Child, Family and Environmental Correlates of Children's Motor Skill Proficiency. Journal of Science and Medicine in Sport, 16(4), 332-336.

Capio, C. M., Sit, S. H. P., \& Abernethy, B. 2011. Fundamental Movement Skills Testing in Children with Cerebral Palsy. Disability and Research, 33(2526), 2519-2528.

Dimyati and Mudjiono. 2006. Belajar dan Pembelajaran. Jakarta: PT Rineke Cipta.

Emerson, E. 2005. Underweight, Obesity and Exercise among Adults with Intellectual Disabilities in Supported Accomodation in Northern England. Journal of Intellectual Disability Research, 49(2): 134-143.

Kenneth, R. Ginsburg. 2007. American Journal Academy of Pediatrics, Vol. 119 No. 1, January 1, 2007). 182-191.

Khodaverdi, Z., Bahram, A., Khalaji, H., \& Kazemnejad, A. 2013. Motor Skill Competence and Perceived Motor Competence: Which Best Predicts Physical Activity among Girls?. Iranian Journal of Public Health, 42, $1145-1150$.

Kihara, I., Hasimoto, R. 2000. Measurement of Vertical Section of Physical Strength in Children with Mental Disabilities. Japaness Journal of Physical Fitness and Sport Medicine, 49, 887.

Kottman, Terry. 2011 .Play theraphy basic and beyond. United States of America: American Counseling Association.

Kustawan, Dedy and Meimulyani. 2016. Know Special Education and Education of Specialized Services and Implementation. East Jakarta: Luxima.

Li, R., Sit, S. H. P., Yu, J. J., Duan, J. Z., Fan, C. M., \& Wong, S. H. S. 2016. Correlates of Physical Activity in Children and Adolescents with Physical Disabilities: A Systematic Review. Preventive Medicine 89, 184193.

Moss, SJ. 2009. Changes in Coronary Heart Disease Risk Profile of Adults with Intellectual Disabilities Following A Physical Activity Intervention. Journal 
of Intellectual Disability Research, 53: 735-744.

Mutiah, D. 2010. Psychology Playing Early Childhood. Jakarta: Kencana.

Parham, L.D., \& L. A. Fazio. 2008. Play in occupational theraphy for children. United States of America; Mosby.

Rosnawati, Ati and Kemis. 2013. Education of Children with Special Needs of Intellectual Disability. East Jakarta: Published; Luxima Metro Media.

Soetjiningsih. 2002. Child Growth. Mold II, EGC. Jakarta.

Stodden, D. F., Goodway, J. D., Langendorfer, S., Roberton, M. A., Rudisill, M. E. \& Garcia, L. E. 2008. A Developmental Perspective on The Role of Motor Skill Competence in Physical Activity:
An Emergent Relationship. Quest, 60, 290-306.

Temple, VA. 2009. Factors Associated with High Levels of Physical Activity among Adults With Intellectual Disability. International Journal of Rehabilitation Research, 32: 89-92.

Widati CH, Sri and Murtadlo. 2007. Adaptive Physical and Sports Education. Jakarta: Ministry of National Education Directorate General of Higher Education Directorate of Manpower.

Yudanto. (2010). Basic Motion Stimulation of Lower Grade Primary School Students. Journal of Indonesian Physical Education, Volume 4, Number 2, November 2007. Faculty of Sport Science, Yogyakarta University. 